\title{
JORNAL TRIBUNA POPULAR E A CONSTRUÇÃO DE UM IDEÁRIO "PROTO-TRABALHISTA" NO AMAZONAS
}

\author{
Amaury Oliveira Pio Junior*
}

\section{RESUMO:}

Neste artigo abordaremos a relação entre o estabelecimento de um grupo político nos anos 30 no Amazonas, vinculado a implantação de um novo modelo sindical proposto por Getúlio Vargas, e as repercussões decorrentes em âmbito Estadual através das páginas do Jornal Tribuna Popular. Propomos transitar entre o diálogo da imprensa escrita e seu uso como meio de difusão de uma proposta Trabalhista que, embora ainda em seu estágio embrionário, já apontava uma preocupação na construção de uma identidade de valores própria.

Palavras-chave: Trabalhismo, Tribuna Popular, Partido Trabalhista Amazonense.

\begin{abstract}
:
In this article we will discuss the relationship between the establishment of a political group in the 1930s in Amazonas state, linked to the implementation of a new union model proposed by Getúlio Vargas, and as repercussions resulting in the state ambit through the pages of Jornal Tribuna Popular. We propose to move between the dialogue of the written press and its use as a means of diffusion of a Labor proposal which, even being in its embryonic stage, already pointed out a concern about construction of an identity of own values.
\end{abstract}

Keywords: Labor; Popular Tribune; Amazonian Labor Party.

\section{Aspectos Gerais do Tribuna Popular}

O período denominado como "Governo Constitucionalista", compreendido entre os anos de 1934 e 1937, caracterizou-se por ser uma fase da História política brasileira entre o fim do Governo Provisório, iniciado por Getúlio Vargas ainda em 1930 e o chamado Estado Novo que seguiria até 1945.

Como elemento importante de promessa da então Revolução de 30, caberia a Getúlio Vargas como mandatário, tornar possíveis as condições para a elaboração de uma nova ordem institucional no Brasil, iniciando pela convocação de uma nova Assembleia Nacional Constituinte.

Em virtude da proximidade destas eleições, o ano de 1933 seria marcado pelo reagrupamento das diversas forças políticas nos Estados, tanto às ligadas as antigas

\footnotetext{
${ }^{*}$ Mestre em História Social pela Universidade Federal do Amazonas, Professor do Centro de Mídias do Governo do Estado do Amazonas. Este artigo é uma adaptação de parte dos resultados de pesquisa da dissertação de Mestrado. E-mail: amaurypio@ hotmail.com
} 
oligarquias que resistiam a Getúlio Vargas, quanto aquelas que haviam aderido prontamente ao Governo Provisório e suas propostas.

Diante deste quadro, no Estado do Amazonas destacaram-se agremiações já consolidadas antes de 1930, como o Partido Republicano do Amazonas (PRA), ao lado dos recém criados Partido Socialista Amazonense (PSA) e Partido Trabalhista Amazonense (PTA).

Quanto a este último, recai nossa atenção haja seu visível atrelamento as pretensões varguistas, especialmente as relacionadas ao estabelecimento de uma regulamentação das regras nas negociações entre patrões, empregados e governo. Além disto caberiam aos sindicatos um novo papel nestas relações, tudo isso ainda em estágio de elaboração e aplicação por parte do Ministério do Trabalho, Indústria e Comércio (MTIC).

A exemplo lembramos a Lei 19.770 de março de 1931, conhecida como Lei da Sindicalização, que intencionava difundir entre a classe trabalhadora urbana a necessidade de vinculação sindical em entidades reconhecidas pelo MTIC. Esta lei pretendia seduzir os trabalhadores a agirem desta forma em troca de uma série de benefícios que posteriormente, seriam "garantidos" pelo governo, como por exemplo, a jornada de oito horas diárias aos operários das indústrias. ${ }^{1}$

O lançamento em 1933 do periódico Tribuna Popular, autointitulado "Órgão de divulgação do Partido Trabalhista Amazonense" veio a este fim, não somente atender os objetivos eleitorais dos Trabalhistas perante a Assembleia Nacional Constituinte, mas ao cabo de seus quatro anos de funcionamento, estabeleceria uma posição de importante ferramenta de aproximação e conscientização do operariado local com o ideário varguista da época.

Cabe aqui mencionar que diversos jornais de ampla circulação em Manaus estavam associados a grupos ou partidos políticos, como nos casos de "O Liberal" e "O Amazonas", ligados ao Partido Liberal do Amazonas ou ainda "A Reação", vinculado ao Partido Republicano Amazonense. ${ }^{2}$

Quanto a imprensa sindical, embora também estivesse presente no Amazonas desde o início do século XX, existia em paralelo ao que definia-se como a "grande imprensa", sendo em sua maioria ligados aos tipógrafos. No entanto não deixavam de exercer o papel de significativo meio de circulação das ideias operárias, conforme aponta Maria Luíza:

\footnotetext{
${ }^{1}$ GOMES, Angela de Castro. A Invenção do Trabalhismo. 3. ed. Rio de Janeiro: Editora FGV, 2005. p. 30-31.

2 SANTOS, Francisco Jorge dos. et al. Cem anos de Imprensa no Amazonas (1851-1950). Catálogo de Jornais. 2. ed. revisada. Manaus: Edua, 1990.p. 132, 122).
} 
(...) os jornais operários não fizeram parte da grande imprensa, porque amiúde lhes faltava recursos financeiros, mas apesar de serem Folhas de um dia na maioria das vezes, com uma produção descontínua e dispersa, foram fundamentais para o conhecimento da labuta dos operários: anseios, reivindicações, denúncias, movimentos e vitórias. ${ }^{3}$

Desta forma, era de se esperar que diante de toda conjuntura nacional oriunda da Revolução de 1930, refletisse em um momento que Manaus vivenciasse uma efervescência na imprensa escrita; principalmente nos meios de comunicação que servissem à circulação dos debates eleitorais.

O lançamento de jornais e sua necessária periodicidade no Amazonas fora, na década de 1920, o reflexo do próprio momento de uma crise econômica refletida pelo fim do Ciclo da Borracha a partir de 1915. Para Alves, circulavam na época "aproximadamente 25 periódicos no Amazonas (...) alguns remanescentes das duas primeiras décadas do século XX, que tiveram seu fim nos anos 30, outros nasceram nessa década de 1930, mas tiveram vida curta". 4

Não nos surpreende, portanto que em seu ano de lançamento o Tribuna Popular contasse então com apenas duas edições.

A periodicidade do jornal, contudo, ganharia impulso no ano seguinte - 1934 quando a partir do dia 15 de maio ocorre sua retomada com edições quinzenais, condição mantida até seu encerramento em abril de 1936.

Quanto a esta retomada, logo nos permite constatar suas pretensões, a exemplo de sua primeira coluna intitulada "Trabalhistas em Forma", onde menciona-se que o Jornal "era agora editado em oficina própria”, dando a entender que anteriormente, o jornal poderia carecer de um espaço mais apropriado para o porte de trabalho que intencionava realizar. Informa-se ainda que a "redação e oficina" funcionavam à Rua Henrique Martins, n 9, esquina com a Rua Lobo D’Almada, em plena área central da capital amazonense. ${ }^{5}$

Pelas informações que obtemos através de suas edições, o financiamento do jornal era assegurado por anúncios e propagandas que dividiam espaço com as notícias e artigos. Nenhum balancete ou prestação de contas foram ali divulgados nas edições a que tivemos acesso. $^{6}$

\footnotetext{
${ }^{3}$ PINHEIRO, Maria Luiza Ugarte. Folhas do Norte: letramento e periodismo no Amazonas (1880-1920). (Tese) Doutorado em História. São Paulo: Pontifícia Universidade Católica de São Paulo, 2001 p. 131.

${ }^{4}$ ALVES, Hosenildo Gato. Imprensa e Poder: A Propaganda Varguista na Imprensa Amazonense (1937-1945). (Dissertação) Mestrado em História Social - Universidade Federal do Amazonas, Manaus: 2009 p. 60.

5 JORNAL TRIBUNA POPULAR, 15 de mai 1934.

${ }^{6}$ Inferimos que, enquanto Órgão de Divulgação do PTA, o Tribuna Popular, assuntos deste tipo, pudessem fazer parte de assuntos internos do Partido, do qual não tivemos acesso as atas.
} 
Informes sobre a prestação de serviços por profissionais liberais, divulgação de diversas marcas de remédios e cigarros, assim como barcos de transporte de linhas nacional e internacional, entre outros anúncios, pareciam ser um meio de assegurar sua periodicidade quinzenal. Nota-se, contudo que, geralmente às vésperas das eleições de1934 e 1935 sua circulação era praticamente diária.

Quanto a sua tiragem, atestamos que os periódicos amazonenses geralmente, não tinha o costume de informar o número de exemplares de suas publicações ${ }^{7}$. Em um caso específico, na edição seguinte ao comício que oficializava a criação do PPA, menciona-se "a tiragem de 3.100 exemplares da Tribuna Popular". ${ }^{\circ}$

Os editores do jornal foram Vivaldo de Palma Lima como redator-chefe, Antônio de Vasconcellos como diretor político e Oscar Costa Rayol como redator-secretário. Embora membros do Partido Trabalhista Amazonense, não participaram como candidatos no período de circulação entre 1933 e 1936. Destes, constatamos ter sido Antônio de Vasconsellos quem mais assinou colunas e artigos, sendo que são os únicos cujos nomes e funções são descritos em todas as edições a que tivemos acesso.

Quanto ao formato do jornal, verificamos que possuía formato de $36 \times 53 \mathrm{~cm}$, composto de 04 páginas, 06 colunas e 01 caderno. Conforme mencionado, sua coordenação era executada por três funcionários, apesar de que a menção de possuírem gráfica própria e coordenarem um sistema de distribuição nos aponta que haviam mais empregados envolvidos, porém não mencionados. ${ }^{9}$

Preocupado em dispor de meios próprios para uma comunicação mais ágil entre Manaus os grandes centros e outras localidades do Estado, o Tribuna Popular informava contar ainda com o endereço telegráfico "Tripopular".

Atender a demanda de um periódico semanal deveras, impunha a seus empreendedores um desafio financeiro considerável. Constatamos ao longo da existência do Tribuna Popular que, diversas estratégias operacionais eram utilizadas para contribuir com o fechamento desta contabilidade. Aliás desde a retomada da impressão em 1934, verifica-se uma preocupação quanto a isto.

A cobrança do valor da edição era de \$200 (duzentos réis), sendo que edições anteriores também eram disponibilizadas ao custo adicional de $\$ 500$ (quinhentos réis). Este

\footnotetext{
${ }^{7}$ RIBEIRO, Priscila Daniele Tavares. Jornal do Commercio: Construtor e Artífice da modernidade em Manaus. (Dissertação) Mestrado em História - Universidade Federal do Amazonas. Manaus, 2014 p.33

8 (JORNAL TRIBUNA POPULAR, 18 de jul. 1935).

${ }^{9}$ SANTOS, Francisco Jorge dos. et al. Cem anos de Imprensa no Amazonas (1851-1950). Catálogo de Jornais. 2. ed. revisada. Manaus: Edua, 1990 p. 203.
} 
era um valor aproximado de um dos maiores jornais de circulação em Manaus, o Jornal do Commercio, o qual cobrava em sua edição diária $\$ 300$ (trezentos réis).

Ao contrário de outros periódicos locais, não apresentava valores diferenciados para capital ou interior, talvez devido a sua precária capilaridade pelas demais cidades do interior do Estado. Na edição de 6 de setembro de 1935, lista-se que o mesmo preço era cobrado na capital e interior, de "assinaturas mensais $1 \$ 000$ (um mil réis). ${ }^{10}$

Desde seu início, o Tribuna Popular também utilizou do expediente de patrocinadores, os quais eram conhecidamente membros do PTA/PPA e outros - ao que nos parece a maioria - simpatizantes ou não dos Partidos.

Alguns anunciantes ligados ao PTA podem ser melhores identificados pelos anúncios de profissionais liberais, como "Dr Vivaldo Lima - médico e advogado"11. Em alguns casos, como o do "Eletricista Ivo - o mais confiável" pouco podemos inferir quanto a esta possibilidade, embora sua presença seja detectada em todas as edições, o que denota ao menos simpatia quanto à proposta do jornal. ${ }^{12}$

Também havia a possibilidade de arrecadação de fundos de menor monta, através de avisos menores, chamados de "publicações particulares" que deveriam "ser contratadas junto a gerência e pagas adiantadamente". 13

Uma indicação de que o Tribuna Popular tinha um alcance social maior do que o público alvo do PTA eram os inúmeros e variados anúncios de maior destaque, cujos espaços que ocupavam eram generosos, a partir da segunda página das edições.

Estas iam desde informes sobre medicamentos e seus benefícios - "Regulador Universal para doenças de senhoras", "Sezonol: contra o impaludismo" - passando por estabelecimentos comerciais, como drogarias "Farmácia Lopes e Drogaria Central" ou ainda estabelecimentos diversos como "Casa da Sorte: Loterias Federal, Casa 22 Paulista (tecidos), Armazém de Ferragens do Mercado J. Soares \& Cia, Grande Armazém Rufino \& Irmãos, Sapataria Iracema, Chapelaria Goulart, Alfaiataria Bezerra, Commercial do Pará - Seguros Marítimos", só para mencionar os de maior frequência em suas páginas. Lembramos também a Fábrica de Cigarros Minerva, que alterava nas edições anúncios de suas variadas marcas, como "Canário, e Chinês". ${ }^{14}$

\footnotetext{
${ }^{10}$ JORNAL TRIBUNA POPULAR, 29 de ago. 1935.

${ }^{11}$ Também redator-chefe do Tribuna Popular.

12 Em nenhuma edição, o "Eletricista Ivo" ou qualquer outro nome com esta inicial fora candidato pelo PTA ou PPA.

${ }^{13}$ JORNAL TRIBUNA POPULAR, 18 de jun. 1934.

14 JORNAL TRIBUNA POPULAR, 18 de jun. e 25 de jul. 1934.
} 
Serviços como de "utilidade pública" eram veiculados em todas as edições, informando saída e chegada de embarcações e seus destinos (algumas destas faziam anúncios individuais em espaços maiores), assim como a cotação nacional e internacional de diversos produtos como carnes de animais silvestres, café, azeite de oliva ou farinha de trigo entre outros.

Também eram mencionados os plantões de farmácias que estariam abertas nos finais de semana, assim como locais de alistamento eleitoral, além de endereços e horários de funcionamentos de órgãos públicos das três esferas.

Por fim, reforçando a política editorial de variar os eixos temáticos tradicionalmente explorados pelo jornal, eram reservados espaços dedicados às atualizações esportivas, onde se notam com mais frequência estar os campeonatos de xadrez e futebol. Em períodos de maior acirramento dado os embates eleitorais, a estes temas eram reservados espaços mínimos como a "Coluna Desportos".

Em certas edições, podemos encontrar balanços de algumas das Caixas de Pensões dos trabalhadores manauaras. Estes últimos levavam duas a três páginas inteiras do jornal, sugerindo que pudessem ser cobradas, o que gerava certa fonte de renda para a manutenção do Tribuna Popular. ${ }^{15}$

Porém, o que podemos perceber ao longo de suas edições, é que o jornal tinha um objetivo maior claramente definido, o qual era difundir a mensagem do grupo político que gravitava em torno do Partido Trabalhista Amazonense. Quanto a esta perspectiva, suas estratégias e resultados, é o que nos leva o tema a seguir.

\section{O Tribuna Popular e a identificação com as propostas varguistas}

Conforme vimos até aqui, Partido Trabalhista Amazonense surge em meio a um contexto singular, onde sob a perspectiva de previsão de uma nova Constituinte Nacional, verifica-se um momento de reorganização de grupos políticos tradicionais ao mesmo tempo que surgem novas agremiações.

Diante disto, o PTA funda como seu órgão de divulgação o periódico Tribuna Popular. Além de suas funções partidárias, o jornal também passa a ser destinado à "orientação das hostes trabalhistas" $"$.

\footnotetext{
${ }^{15}$ Os Portuários de Manaus publicaram um extenso e detalhado Relatório Financeiro sobre sua Caixa de Aposentadoria e Pensões, onde utilizaram diversas tabelas como forma de "prestar contas aos associados" (JORNAL TRIBUNA POPULAR, 27 abr. 1935).

${ }^{16}$ JORNAL TRIBUNA POPULAR, 15 de mai. 1934.
} 
Mas afinal a quem especificamente referia-se serem estas "hostes trabalhistas"? Em continuidade o jornal as identifica como:

Homens de trabalho, que constituem ser uma parcela numerosa da massa popular, que até estes últimos tempos, estavam acostumadas a servirem de degrau para onde o político com suas lábias subiram para se elevar ás altas posições. Porém os tempos mudaram e esses homens de trabalho não se sujeitam a servirem de degrau a mais ninguém, pois hão de encontrar entre seus companheiros e camaradas quem possa indicar para ocupar as posições políticas. ${ }^{17}$

Nota-se, portanto que seu público-alvo por predileção seriam elementos oriundos da classe trabalhadora, inferindo desta forma que o maior mantenedor do Tribuna Popular ou seja, o Partido Trabalhista Amazonense teria a intenção de manter neste momento, maior aproximação com este extrato do eleitorado amazonense.

Os efeitos práticos do PTA no campo político fora atingido pela conquista de uma das quatro vagas que o Amazonas teria na Assembleia Nacional Constituinte, com a vitória do capitão de fragata Luiz Tirelli.

Figura bastante ligada a fundação do Partido Trabalhista Amazonense, Tirelli parecia ter tido uma carreira bastante ligada as propostas do PTA, havendo exercido funções como militar e liderança sindical ao participar da criação em 1912, da primeira Federação Marítima do Brasil. Nesta mesma época, já encontrava-se em serviço no Amazonas, onde alternaria com passagens no Rio Grande do Norte, Pará e provavelmente outros estados. ${ }^{18}$

Lideranças como Tirelli, reforçam a preocupação do grupo político em afirmar forte vinculação com as questões trabalhistas, e a importância que o Tribuna Popular tinha no sentido de divulgar aos seu público direto.

O país ainda vivia os reflexos dos acontecimentos de 1930 e a instabilidade dali decorrente. Quanto a isto, Angela Gomes identifica que "até 1933 boa parte da regulamentação trabalhista já estava criada", porém, contudo a adesão sindical ainda era opcional e encontrava forte resistência principalmente nas entidades sob controle de lideranças comunistas, opostas a imposição das regras estabelecidas pelo Ministério do Trabalho. ${ }^{19}$

Fazia-se desta forma imprescindível que houvesse uma convincente divulgação dos benefícios daqueles cujos sindicatos amazonenses ainda não haviam sido reconhecidos pelo MTIC , além de constituir uma eficiente orientação para aqueles que aderissem ao novo

\footnotetext{
17 JORNAL TRIBUNA POPULAR, 15 de mai. 1934.

${ }^{18}$ FUNDAÇÃO GETÚLIO VARGAS/CPDOC. Dicionário Histórico-Biográfico Brasileiro. Rio de Janeiro: 2001 p. 3396.

${ }^{19}$ GOMES, Angela de Castro. A Invenção do Trabalhismo. 3. ed. Rio de Janeiro: Editora FGV, 2005. p.164
} 
modelo sindical. É neste momento que o Tribuna Popular reitera um papel contundente como veículo destes propósitos.

\section{O Tribuna Popular como veículo de divulgação e instrução Trabalhista}

O atrelamento do Tribuna Popular com a figura de Getúlio Vargas é notório desde seu início, como podemos averiguar já na edição no 4 , a qual traz em destaque a fotografia de Getúlio Vargas sob a legenda: "Dr. Getúlio Vargas, candidato dos Trabalhistas do Brasil à Presidência Constitucional da República". ${ }^{20}$

Defere-se desta mensagem a tentativa de atrelar o PTA à figura de Vargas, além de projetar o leitor a mensagem de que "os Trabalhistas do Brasil” eram um segmento político que extrapolava as fronteiras amazonenses tendo como liderança nacional o próprio Vargas.

De fato esta aproximação tornava-se importante naquela primeira metade da década, haja vista o Trabalhismo enquanto conjunto de um ideário e política de Estado, ainda encontra-se em processo de gestação, somente vindo a consolidar-se como tal alguns anos depois.

A tática de reproduzir trechos ou discursos inteiros do mandatário nacional fora um expediente constantemente utilizado pelo Tribuna Popular, quase sempre relacionando Getúlio Vargas a quem "defende o povo trabalhador brasileiro". ${ }^{21}$

Outras indicação quanto ao viés orientativo do periódico pode ser notado quando pontuava em destaque as adesões das entidades locais à política sindical pretendida pelo MTIC. Em um destes momentos se anuncia a criação de uma nova entidade, a Federação Trabalhista do Amazonas, como congregadora das forças sindicais do Amazonas em torno da nova regulamentação:

Em sessão solene, com a presença de todos os delegados das antigas associações federadas e sob a presidência do nosso amigo Francisco Caetano de Andrade, presidente do Sindicato dos Cigarreiros e da União Operária Amazonense, instalou-se oficialmente a nova entidade proletária, cuja carta constitucional acaba de ser remodelada, nos termos da lei de sindicalização, devendo os novos estatutos seguir para o sul no próximo avião da Panair, para serem submetidos a aprovação do sr. Ministro do Trabalho, Industria e Comercio, na forma da legislação vigente. A nova entidade constitui seus procuradores junto ao Ministério do Trabalho, aos nossos prezados amigos, deputado Luiz Tirelli e João Antonio Jacob, presidente do sindicato dos empregados da Light e Companhias Associadas $(\ldots) .^{22}$

\footnotetext{
${ }^{20}$ JORNAL TRIBUNA POPULAR, 21 de mai. 1934.

${ }^{21}$ JORNAL TRIBUNA POPULAR, 24 de fev. 1936.

22 JORNAL TRIBUNA POPULAR, 04 de jun. 1934. (grifo nosso)
} 
Também é possível identificar nas páginas do jornal a repercussão de efusivos discursos por parte das lideranças trabalhistas locais, principalmente nos eventos que envolviam a chegada das "cartas sindicais". Por trás destes documentos encontramos a materialização da adesão comprovada das entidades e sindicatos laborais agora sob as regras impostas pelo Ministério do Trabalho.

No ano de 1934 podemos apontar como exemplos, a menção das cartas sindicais do Sindicato de Empregados em Tração, Força e Luz (antigo sindicato Diaristas da Manaós Tramways), o Sindicato dos Metalúrgicos de Manaus e o Sindicato dos Leiteiros do Sindicato dos Alfaiates e Costureiras, e dos Remadores de Manaus. ${ }^{23}$

A necessidade do Jornal em informar sobre crescente adesão de entidades leva ao lançamento da coluna intitulada "Redutos Trabalhistas", na qual eram informados os nomes dos sindicatos e outras associações laborais, que ombreavam apoio ao Partido Trabalhista Amazonense.

Em seu primeiro aparecimento, a coluna tratou de apontar algumas das principais entidades então ligadas ao PTA:

Federação Trabalhista do Amazonas, Sociedade Beneficente dos Taifeiros, Sindicato dos Empregados Leiteiros, Sindicato dos Empregados em Força, Tração e Luz, Sindicato dos Trabalhadores Gráficos no Amazonas, Sindicato dos Empregados em Construção Civil, Sindicato dos Metalúrgicos de Manaus, Sindicato Misto dos Barbeiros de Manaus, Centro Proletário do Amazonas, Sindicato dos Trabalhadores, Sindicato dos Operarios Cigarreiros de Manaus, Sociedade Benficiente União Operária, Sociedade Beneficiente União dos Foguistas do Amazonas e sucursal em Itacoatiara. ${ }^{24}$

Ressalta-se a fidelidade do periódico com a proposta de ser o "Órgão de divulgação do Partido Trabalhista Amazonense" e indo além, percebe-se a constituição de um trançado, uma espécie de comunhão entre interesses político-partidários e a instalação do novo modelo sindical no Estado do Amazonas.

O espaço "Redutos Trabalhistas" também visava sensibilizar através de um discurso racionalista os próprios trabalhadores quanto as "vantagens" que passariam a usufruir sob a nova política sindical:

Em reunião ordinária, o Sindicato dos Gráficos, sob a fala dos camaradas Luiz Corrêa, (...) comentaram acerca das vantagens do pedido de sindicalização da sociedade, mostrando a todos os presentes, as vantagens que advém a classe esta medida. $O$ procurador do sindicato ao Rio de

\footnotetext{
${ }^{23}$ JORNAL TRIBUNA POPULAR, 11 de set. 1934.

24 JORNAL TRIBUNA POPULAR, 06 de jul. 1934.
} 
Janeiro, o sr. João Antonio Jacob, espera para breve dias o registro da Associação no Ministério do Trabalho. ${ }^{25}$

Outro evento bastante destacado eram as entregas das Carteiras de Trabalho oriundas diretamente do MTIC e distribuídas pela Inspetoria Regional do Trabalho ${ }^{26}$. De início são mencionadas pelo Tribuna Popular a entrega de algumas dezenas de Carteiras de Trabalho por mês. Porém entre 1935 e 1936 este volume torna-se cada vez mais numeroso chegando em janeiro de 1936 "mais de 300 carteiras" encontrando-se à disposição para sua devida retirada. $^{27}$

Em levantamento das edições de 1934 a 1936, podemos aferir a emissão e entrega de pouco mais de 2.500 destes documentos em Manaus. Parte deste substancial crescimento é creditado no empenho de políticos do PTA, como o deputado Luiz Tirelli em agilizar maior celeridade junto ao Ministério do Trabalho quanto a confecção e entrega das Carteiras ${ }^{28}$.

Ainda quanto ao caráter instrutivo do Tribuna Popular junto aos trabalhadores, estão as publicações em que se reforça a menção a casos de diversos sindicatos que já se beneficiavam do expediente jurídico proporcionado pela adesão ao MTIC como recurso na solução de problemas trabalhistas.

Um dos casos descritos trata de uma empresa de produção de erva mate, sediada em Curitiba, que havia sido acionada "pelo Sindicato dos Operários Hervateiros, que através do Ministério do Trabalho, buscava reverter a demissão de diversos funcionários da empresa F. F. Fontana \& $\mathrm{Cia}^{\text {"29 }}$ Ali também foram especificados diversos pontos baseados no artigo $\mathrm{n}^{\mathrm{o}} 13$ do decreto 19.770 de março de 1931, quanto aos direitos que o trabalhador sindicalizado poderia recorrer, contra demissões ilegais.

Situações semelhantes também já eram relatadas a nível local, como quando o Sindicato dos Metalúrgicos de Manaus se solidarizava com os trabalhadores gráficos contra o

\footnotetext{
25 JORNAL TRIBUNA POPULAR, 01 de abr. 1935.

${ }^{26}$ A criação deste documento foi instituída pelo decreto $\mathrm{n}^{\mathrm{o}} 21.175$, de 21 de março de $\underline{1932}$, e, posteriormente, regulamentada pelo decreto 22.035, de 29 de outubro de 1932. Em 1934, o governo do presidente Getúlio Vargas tornou a carteira de trabalho obrigatória para fins de consolidação dos direitos trabalhistas Convém, aqui, porém, apontar uma observação de Ângela Gomes, de que "a nova carteira profissional visava substituir as antigas, antes emitidas pelos sindicatos, que tinham por fim identificar o portador como trabalhador com ofício, garantido pelo sindicato. As novas carteiras, agora emitidas pelo DNT (Departamento Nacional do Trabalho), transformaram-se em documento necessário para associação em sindicato, gozo de férias, apresentação de queixas nas Juntas de Conciliação e Julgamento e obtenção de empréstimo nas Caixas de Aposentadorias e Pensões”. (GOMES, 2007 p.16)

27 JORNAL TRIBUNA POPULAR, 20 de jan. 1936.

28 JORNAL TRIBUNA POPULAR, 20 de ago. 1934

${ }^{29}$ JORNAL TRIBUNA POPULAR, 28 de mai. 1934.
} 
fechamento da Amazon Enginering empresa, a qual justificava "devido a não suportar cobrir para com as obrigações da nova legislação trabalhista". ${ }^{30}$

Em outro caso, o periódico publica uma reclamação enviada pelo Sindicato dos Operários de Serrarias, quanto à ameaça de fechamento das atividades da empresa Serrarias Pereira. Tal situação fora gerada pela exigência de seus funcionários quanto a aumentos salariais. A Serraria dizia não poder cumprir a exigência e simplesmente fecharia suas portas. $\mathrm{Na}$ argumentação do Sindicato junto à empresa, nota-se que "o caso fora levada a Inspetoria do Trabalho, para que ali, a questão fosse harmoniosamente resolvida". ${ }^{31}$

Percorrendo mais alguns volumes do Jornal, nota-se que os próprios sindicatos também recebiam instruções quanto ao cumprimento de dispositivos obrigatórios, como vemos a seguir:

Todos os Sindicatos são obrigados, de acordo com o disposto no art. 22 do decreto 24.694, de 12 de julho de 1934, e em obediência ás recomendações constantes (...), a enviar a autoridade competente, até Março de cada ano, um Relatório do acontecido no ano civil anterior, dentro do modelo oficial. Assim sendo, ficam avisados os Sindicatos locais para isso cumprir, afim de aprovarem seu funcionamento regular. ${ }^{32}$

Esta função exercida pela Inspetoria Regional do Trabalho corrobora com Vianna, quando este afirma

"logo que incluídos na estrutura corporativa, os sindicatos estavam sujeitos à permanente vigilância estatal por meio de representantes do Ministério do Trabalho, que detinham a faculdade de assistir as assembleias e o poder de polícia de investigar sua contabilidade". 33

Cabe aqui lembrar o importante papel das Inspetorias do Trabalho no conjunto do novo modelo sindical varguista. Através do Tribuna Popular esta é apresentada como um órgão de poder que detinha prerrogativas de fazer valer a legislação, de acordo com o que verifica-se em um típico informe da Coluna Redutos Trabalhistas:

Por terem infringido dispositivos da legislação social-trabalhista, foram autuadas as firmas seguintes: H. Batista, fazendas; J. Fontenelle, cinema; Manoel Fonseca, produtos de leite; Mattos Areosa, comissões; Victoria Marques, mercearia; Marques \& Gaspar, livraria. (...) FÉRIAS: Por não terem pago férias devidas a seus empregados, foram intimadas a fazer isso, as seguintes firmas: Camello, Irmão \& Cia, fabrica de cigarros, Marques \& Cia, marchante; L. O. Bastos, idem; Eduardo Peres, idem; Gonzaga Palmeira

\footnotetext{
${ }^{30}$ JORNAL TRIBUNA POPULAR, 21 de out. 1935.

${ }^{31}$ JORNAL TRIBUNA POPULAR, 09 dez. 1935.

32 JORNAL TRIBUNA POPULAR, 02 de mar. 1936.

${ }^{33}$ VIANNA, Luís Werneck. Liberalismo e sindicato no Brasil. 2. ed. , Rio de Janeiro: Paz e Terra, 1978. p.147.
} 
\& Queiróz, idem; Segismundo Pinheiro, idem; Manoel Marques de Souza, idem. $(. . .)^{34}$

Reitera-se mais uma vez a estruturação do edifício jurídico do novo modelo sindical varguista nos Estados, através de uma espécie de tripé, cujas bases estavam engendradas nas ações de um aparato político-partidário, aliançados conjuntamente com um recém criado órgão burocrático federal.

\section{CONSIDERAÇÕES FINAIS}

A História do Brasil e a história da imprensa caminham juntas, se autoexplicam, alimentam-se reciprocamente, integrando-se num imenso painel. Nesse cenário, muitas vezes os personagens são exatamente os mesmos, na imprensa, na política e nas instituições. [...] Não há como escrever sobre a história da imprensa sem relacioná-la com a trajetória política, econômica, social e cultural do país. ${ }^{35}$

As páginas do Jornal Tribuna Popular, ao longo de suas 116 edições traz em seu conjunto o valor de um contexto histórico brasileiro que embora possa ser aqui identificado como um proto-trabalhismo, certamente nos lega o retrato de um importante período que antecede a instituição definitiva das teses Trabalhistas que para Paranhos somente se caracterizaria enquanto componente ideológico uniforme após $1940 .^{36}$

Além de exteriorizar as primeiras articulações no Amazonas envolvendo o novo modelo sindical que se construía no país, ao mesmo tempo suas páginas nos sinalizam um tempo de preocupações e indefinições quanto a idealização uma identidade trabalhista, intencionada desde em suas primeiras edições:

Já não é mais tempo de continuar estacionária a classe trabalhista. É o momento de cooperar, dentro da ordem e fraternidade, pela completa reivindicação dos nossos direitos e pela perfeita segurança de nosso futuro. A todo trabalhador consiste o direito de organização, por isso não deve temer a qualquer injunção de adestrados corruptores do bem coletivo. (...) E, por conseguinte, trabalhadores, somente com a socialização coletiva que se podem alcançar as nossas reivindicações. (...) Precisamos definir-nos,

\footnotetext{
${ }^{34}$ JORNAL TRIBUNA POPULAR, 20 de jan. 1936.

${ }^{35}$ LUCA, T. R. de (Org.) ; MARTINS, A. L. (Org.) . História da Imprensa no Brasil (co-organização Ana Luiza Martins). 1. ed. São Paulo: Contexto, 2008, v. 1. p. 08

${ }^{36}$ PARANHOS, Adalberto. O Roubo da Fala. Origens da ideologia do trabalhismo no Brasil. 2. ed. São Paulo: Boitempo Editorial, 2007 p. 26.
} 
trabalhistas, para ter um Brasil maior, digno do lugar que lhes compete perante os demais países do mundo! ${ }^{37}$

Vicissitudes que se seguiriam - como a fusão entre o Partido Trabalhista de Luiz Tirelli e o Partido Socialista de Álvaro Maia tendo por finalidade a recomposição das forças pró-Vargas a nível Estadual em 1935 - no entanto, não pareceram desanimar as intenções identitárias dos trabalhistas.

Isto é confirmado na manutenção do título jornal como Tribuna Popular - mesmo após a fusão PTA/PSA - assim como sua periodicidade quinzenal até meados de 1936, quando encerra suas atividades sem contudo expor quaisquer causas.

Por todos estes aspectos, percebemos a frente o desafio de uma maior ampliação sobre este tema, inclusive em âmbito nacional, sob as perspectivas encontradas em outras regiões do país. São estas a nosso ver, ainda pouco exploradas, contudo de interessantes indispensáveis como componentes para uma análise de um importante período de transformações no mundo sindical brasileiro.

\footnotetext{
${ }^{37}$ JORNAL TRIBUNA POPULAR, 22 de abr 1935.
} 


\section{FONTES:}

Jornal Tribuna Popular. Manaus: maio de 1933 - abril de 1936.

\section{REFERÊNCIAS:}

FUNDAÇÃO GETÚlIO VARGAS/CPDOC. Dicionário Histórico-Biográfico Brasileiro, Rio de Janeiro: 2001.

GOMES, Angela de Castro. A Invenção do Trabalhismo. 3. ed. Rio de Janeiro: Editora FGV, 2005.

LUCA, T. R. de (Org.); MARTINS, A. L. (Org.) . História da Imprensa no Brasil (coorganização Ana Luiza Martins). 1. ed. São Paulo: Contexto, 2008.

HOBSBAWM, Eric. Mundos do Trabalho. Rio de Janeiro: Paz e Terra, 2000.

PARANHOS, Adalberto. O Roubo da Fala. Origens da ideologia do trabalhismo no Brasil. 2. ed. São Paulo: Boitempo Editorial, 2007.

PINHEIRO, Maria Luiza Ugarte. Nos Meandros da Cidade: cotidiano e trabalho na Manaus da borracha, 1880-1920. XIV Simpósio Nacional de História - ANPUH 2007. Anais. Disponível em: http://snh2007.anpuh.org/resources/content/anais/Maria\%20Luiza\%20Ugarte\%20Pinheiro.pd. f. Acessado em: 02 de abr. 2015.

PINHEIRO, Maria Luiza Ugarte. A Cidade Sobre os Ombros: Trabalho e Conflito no Porto de Manaus (1899-1925). Manaus: Edua, 1999.

PINHEIRO, Maria Luiza Ugarte. Folhas do Norte: letramento e periodismo no Amazonas (1880-1920). (Tese) Doutorado em História. São Paulo: Pontifícia Universidade Católica de São Paulo, 2001.

SANTOS, Francisco Jorge dos. et al. Cem anos de Imprensa no Amazonas (1851-1950). Catálogo de Jornais. 2. ed. revisada. Manaus: Edua, 1990.

SANTOS, Roberto Araújo de Oliveira. História Econômica da Amazônia (1800-1920). (Dissertação) Faculdade de Economia e Administração Universidade de São Paulo: 1977.

VIANNA, Luís Werneck. Liberalismo e sindicato no Brasil. 2. ed. , Rio de Janeiro: Paz e Terra, 1978. 